\title{
Direct Thrombectomy versus Bridging for Patients with Emergent Large-Vessel Occlusions
}

\author{
Ronen R. Leker ${ }^{a}$ Jose E. Cohen ${ }^{b}$ David Tanne ${ }^{c}$ David Orion ${ }^{c}$ \\ Gregory Telman $^{d}$ Guy Raphaelie Jacob Amsalem ${ }^{d}$ Jonathan Y. Streifler ${ }^{\mathrm{e}}$ \\ Hen Hallevi $^{f}$ Pavel Gavriliuc ${ }^{a} \quad$ Natan M. Bornstein ${ }^{f}$ Anat Horev ${ }^{g}$ \\ Nour Eddine Yaghmour ${ }^{a} \quad$ NASIS-REVASC Study Group

\begin{abstract}
a Department of Neurology, Hadassah-Hebrew University Medical Center, Jerusalem, Israel;
${ }^{b}$ Department of Neurosurgery, Hadassah-Hebrew University Medical Center, Jerusalem, Israel; ' Chaim Sheba Medical Center, Tel-Hashomer, Israel; ${ }^{d}$ Rambam Medical Center, Haifa, Israel; ${ }^{e}$ Rabin Medical Center, Petach Tikva, Israel; ${ }^{f}$ Tel-Aviv Sourasky Medical Center,
\end{abstract} \\ Tel Aviv, Israel; ${ }^{9}$ Soroka Medical Center, Beer Sheva, Israel
}

\section{Keywords}

Reperfusion · Stroke · Stentriever - Endovascular treatment - Thrombolysis

\begin{abstract}
Background and Aims: Patients with emergent large-vessel occlusion (ELVO) that present earlier than $4 \mathrm{~h}$ from onset are usually treated with bridging systemic thrombolysis followed by endovascular thrombectomy (EVT). Whether direct EVT (dEVT) could improve the chances of favorable outcome remains unknown. Methods: Consecutively, prospectively enrolled patients with ELVO presenting within $4 \mathrm{~h}$ of onset were entered into a National Acute Stroke Registry of patients undergoing revascularization. Patients treated with bridging were compared to those treated with dEVT. Excellent outcome was defined as having a modified Rankin Scale score $\leq 1$ at 90 days following stroke. Results: Out of 392 patients that underwent thrombectomy, 270 (68\%) presented within $4 \mathrm{~h}$ and were included. Of those, 159 (59\%) underwent bridging and $111(41 \%)$ underwent dEVT. Atrial fibrillation and congestive heart failure were more common in the dEVT group (43 vs. $30 \%, p=0.04$ and 20 vs. $8 \%, p=0.009$, respectively), but other risk factors, demographics, stroke severity and subtypes as well as baseline vessel patency state and time metrics did not differ. Excellent target vessel recanalization defined as $\mathrm{TICl} 3$ (thrombolysis in cerebral infarction score) was more common in the dEVT group (75 vs. $61 \%, p=0.03)$, but in-hospital mortality, discharge destinations, short- and long-term excellent outcome rates did not differ. On multivariate regression analysis, treatment modality did
\end{abstract}

R.R. Leker, MD

Department of Neurology, Hadassah-Hebrew University Medical Center PO Box 12000

Jerusalem 91120 (Israel)

E-Mail leker@hadassah.org.il 
not significantly modify the chances of excellent outcome at discharge (OR $0.7 ; 95 \% \mathrm{Cl} 0.3-1.5$ ) or at 3 months (OR $0.7895 \% \mathrm{Cl} 0.4-1.4)$. Conclusions: The chances of attaining excellent functional outcomes are similar in ELVO patients undergoing dEVT or bridging.

(c) 2018 S. Karger AG, Basel

\section{Introduction}

Emergent large-vessel occlusion (ELVO) secondary to internal carotid or proximal middle cerebral artery occlusions may lead to malignant infarctions that are associated with high mortality rates and poor outcome [1]. Intravenous tissue plasminogen activator (tPA) has limited efficacy in such patients [2-5] but endovascular therapy (EVT) has recently proven effective in several randomized prospective studies [6-11]. Administration of intravenous tPA followed by EVT is the procedure of choice for most patients with large-vessel occlusion [12-15]. Rapid target vessel recanalization is associated with higher chances for favorable outcome in patients with large-vessel occlusion $[16,17]$ and therefore early direct EVT (dEVT) may be advantageous in these patients by shortening the time to reperfusion $[18,19]$. Several recent studies looked at individual or pooled data from recent observational or randomized studies yielding conflicting results [20-26]. Thus, while most did not find differences in outcome between dEVT and bridging [20,22, 24], some found advantages for dEVT $[21,25]$, while still others were able to detect benefit for bridging over dEVT [26]. In a recent topical review article summarizing the data up to date, there were no conclusive recommendations that could be drawn regarding which strategy was better but it was noted that dEVT may be noninferior to bridging [27]. The aim of the current report was to evaluate whether dEVT is superior to bridging in achieving excellent outcomes among patients with ELVO enrolled in a nationwide prospective database.

\section{Patients and Methods}

Patients undergoing EVT and/or thrombolysis were prospectively included in the National Acute Stroke Israeli Survey of Patients Undergoing Revascularization (NASIS-REVASC) in 6 comprehensive stroke centers between 1/2014 and 3/2016. Institutional review boards approved the study in each of the participating institutions. The diagnosis of ELVO with either internal carotid or proximal middle cerebral artery occlusions had to be established clinically and proven on vascular imaging. For the current analysis, we specifically included patients that underwent EVT and presented to the emergency department within $4 \mathrm{~h}$ from symptom onset in order to maintain a homogeneous group of patients. Patients that improved following systemic thrombolysis and were thus not considered as candidates for EVT were not included in this analysis. We did not use any specific radiological inclusion criteria other than stroke with internal carotid or middle cerebral artery occlusion and/or perfusion deficit on CT corresponding to this vascular territory. Patients transferred to treating centers from other hospitals were included if they met the criterion of presentation to the center performing the endovascular treatment of less than $4 \mathrm{~h}$ from symptom onset. We specifically used this time point in order to obtain a more homogeneous group of patients thus allowing treatment with tPA within $4.5 \mathrm{~h}$ from symptom onset in all included patients.

We accrued data based on a standardized questionnaire that was used in all participating centers. Data included vascular risk profile, time metrics, infarct etiology classified according to TOAST criteria [28], neurological deficits determined with the NIH Stroke Scale (NIHSS), and functional deficits before admission and at 90 days following infarct determined with the modified Rankin Scale (mRS) score.

Radiological parameters were not available for analysis at a central core laboratory for this study and the extent of infarction was quantified locally at each center according to conventional measures such as $\geq 1 / 3$ of the middle cerebral artery territory or with the use of the Alberta Stroke Program Early CT Score (ASPECTS) scale as per individual institutional protocols. Data was analyzed according to whether or not the patients received tPA prior to EVT (bridging vs. dEVT). 


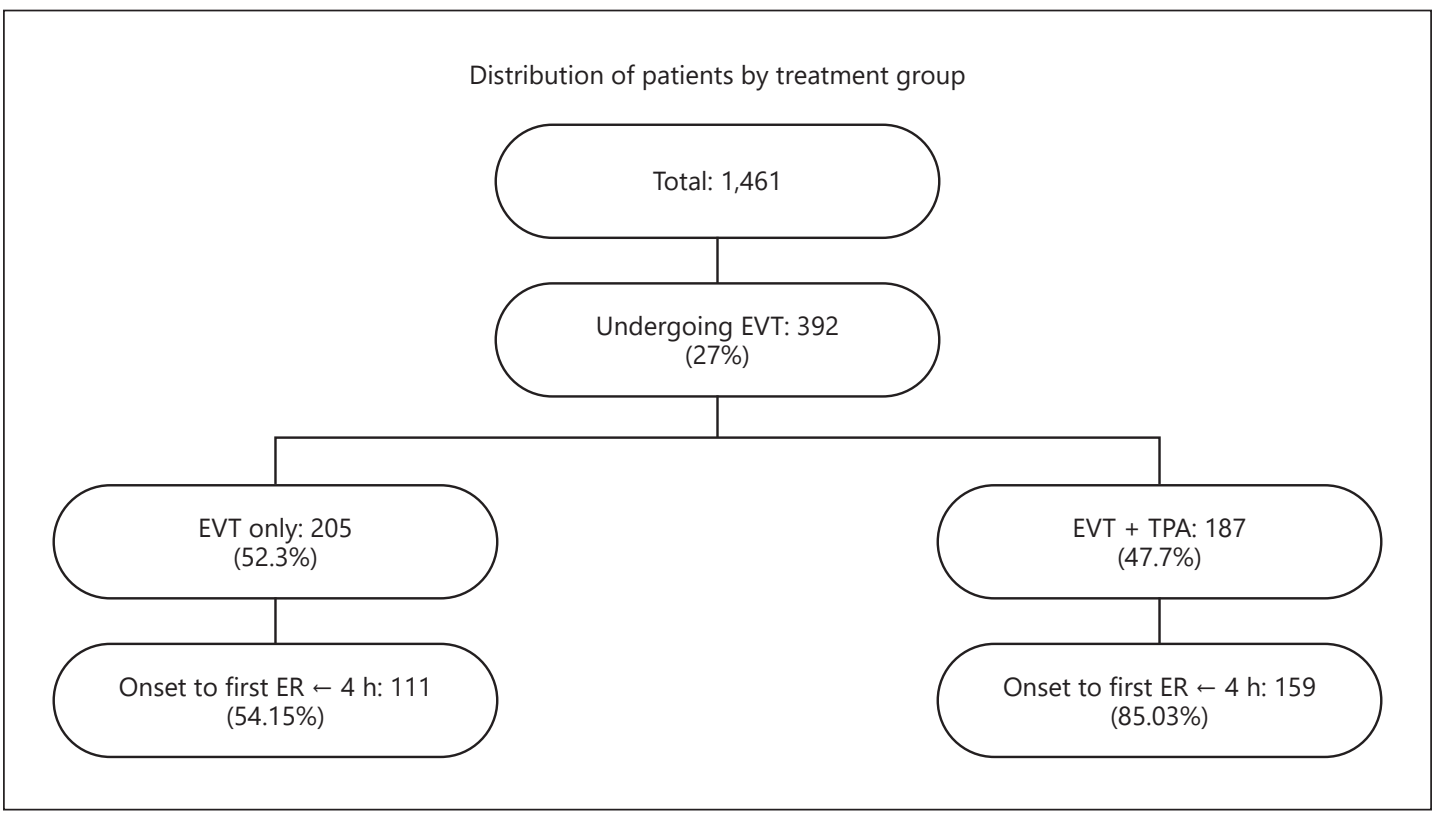

Fig. 1. Distribution of patients treated with EVT in the NASIS-REVASC.

Therapeutic decisions of whether to bridge or go directly to the angio suite for dEVT were made at the discretion of the treating physician in each participating institution on an individual basis. Patients with contraindications to tPA (e.g., international normalized ratio $>1.7$, known bleeding tendency, recent major surgery etc.) were routinely referred to dEVT. Patients who failed to show significant improvement on the NIHSS at the end of tPA infusion were transferred to the angio suite for EVT per local protocols at each center and clinical discretion of the treating physician (e.g., failure to achieve significant improvement as defined by a drop of less than 8 points on the NIHSS from presentation) [29].

Endovascular procedures were performed according to the treating center's protocols. Use of both stentrievers and primary aspiration devices was allowed.

The outcome parameters for this study were survival and functional outcome at 90 days following stroke. Excellent outcome was defined as an mRS score $\leq 1$ at discharge and 3 months following stroke. mRS was evaluated at the participating centers as part of ongoing follow-up of the patients. Vessel patency was classified with the thrombolysis in cerebral infarction (TICI) scale [30]. The safety outcome measures were the percentage of overall intracerebral hemorrhage and symptomatic intracerebral hemorrhage as per participating center protocols with the most widely used being the ECASS3 criteria [31]. Outcome data was analyzed for patients included in the database up to December 2016.

Statistical analysis was performed using R statistics [32]. For univariate analysis, patients were compared using $\chi^{2}$ tests for categorical variables and Student's $t$ test or the Mann-Whitney test for continuous variables. We then used multivariate logistic regression analysis models that included treatment allocation (bridging vs. dEVT), admission NIHSS (per point), age (per year), gender, time to endovascular treatment, and stroke subtype to determine the effects of these variables on defined specific outcomes per model including survival, favorable recanalization (TICI $2 b-3$ ), and favorable outcome.

\section{Results}

Of the 1,461 patients included in the NASIS-REVASC, 392 underwent EVT. Of those, 270 presented within $4 \mathrm{~h}$ and were included in the analysis (Fig. 1). Of those, 159 (59\%) underwent bridging with tPA prior to EVT and 111 (41\%) underwent dEVT (Fig. 1). Of note, 7 (6\%) of the 111 patients that underwent dEVT had absolute contraindications to tPA. Atrial fibril- 
Table 1. Baseline characteristics in patients with ELVO treated with bridging or dEVT

\begin{tabular}{lccc}
\hline & $\begin{array}{l}\text { dEVT } \\
(n=111)\end{array}$ & $\begin{array}{l}\text { EVT + tPA } \\
(n=159)\end{array}$ & $p$ \\
\hline Age (mean \pm SD), years & $67.4 \pm 15.5$ & $68.1 \pm 1$ & 0.66 \\
Men & $58(2)$ & $91(57)$ & 0.49 \\
History and risk factors & $75(69)$ & $111(70)$ & 0.90 \\
$\quad$ Hypertension & $50(45)$ & $78(50)$ & 0.51 \\
$\quad$ Dyslipidemia & $33(30)$ & $50(32)$ & 0.87 \\
$\quad$ Diabetes mellitus & $12(11)$ & $22(14)$ & 0.65 \\
Obesity, BMI>30 & $19(18)$ & $30(19)$ & 0.98 \\
Current smoking & $47(43)$ & $47(30)$ & 0.04 \\
$\quad$ Atrial fibrillation & $22(20)$ & $13(8)$ & 0.001 \\
$\quad$ Congestive heart failure & $8(7)$ & $17(10)$ & 0.45 \\
$\quad$ Prior stroke & $1(1)$ & $3(2)$ & 0.89 \\
$\quad$ Peripheral arterial disease & $16[12,20]$ & $16.00[13,19]$ & 0.34 \\
\hline Admission NIHSS score & $62(56)$ & $75(47)$ & \\
Stroke subtype & $17(15)$ & $32(20)$ & \\
$\quad$ Cardioembolic & $32(29)$ & $52(33)$ & 0.26 \\
$\quad$ Large-vessel atherosclerosis & $4.6 \pm 2.1$ & $4.3 \pm 1.5$ & 0.30 \\
$\quad$ Other/undetermined & $42.6 \pm 39$ & $48.5 \pm 40$ & \\
Onset EVT (mean \pm SD), $h$ & EVT recanalization (mean \pm SD), min & &
\end{tabular}

NIHSS, National Institutes of Health Stroke Scale. Figures are $n(\%)$, mean \pm SD or median [IQR].

Table 2. Outcome parameters in patients with ELVO treated with bridging or direct EVT

\begin{tabular}{llcl}
\hline & $\begin{array}{l}\text { dEVT } \\
(n=111)\end{array}$ & $\begin{array}{l}\text { EVT + tPA } \\
(n=159)\end{array}$ & $p$ \\
\hline TICI score 2b-3 & $89(87)$ & $123(82)$ & 0.34 \\
TICI score 3 & $76(74)$ & $91(61)$ & 0.03 \\
Major early recovery $^{\mathrm{a}}$ & $27(30)$ & $28(30)$ & 1.00 \\
NIHSS, day 1<2 $_{\text {In-hospital mortality }}$ & $12(13)$ & $11(9)$ & 0.49 \\
mRS score at discharge 0-1 & $24(22)$ & $26(16)$ & 0.88 \\
Home discharge $_{\text {mRS score at 3 months 0-1 }}{ }^{\mathrm{b}}$ & $28(31)$ & $33(28)$ & 0.87 \\
\hline
\end{tabular}

mRS, modified Rankin Scale; NIHSS, National Institutes of Health Stroke Scale; TICI, thrombolysis in cerebral infarction. Figures in parentheses are percentages.

a Defined as change of 8 points on the NIHSS scale [21] or NIHSS 0-1 on day $1 .{ }^{\mathrm{b}}$ Data available for 73 patients in the EVT group and 103 in the bridging group.

lation and congestive heart failure were more common in the dEVT group ( 43 vs. $30 \%, p=$ 0.04 and 20 vs. $8 \%, p=0.009$, respectively) but other risk factors, demographics, stroke severity, and subtypes as well as baseline and final TICI scores and time to thrombectomy did not differ between the groups (Table 1). Time to groin puncture or groin puncture to recanalization did not differ between the groups (Table 1). When comparing patients transferred from a primary center to those treated directly at the tertiary centers, the time to EVT was 
Fig. 2. Distributions of different $\mathrm{mRS}$ categories in patients treated with bridging or dEVT in the NASIS-REVASC.

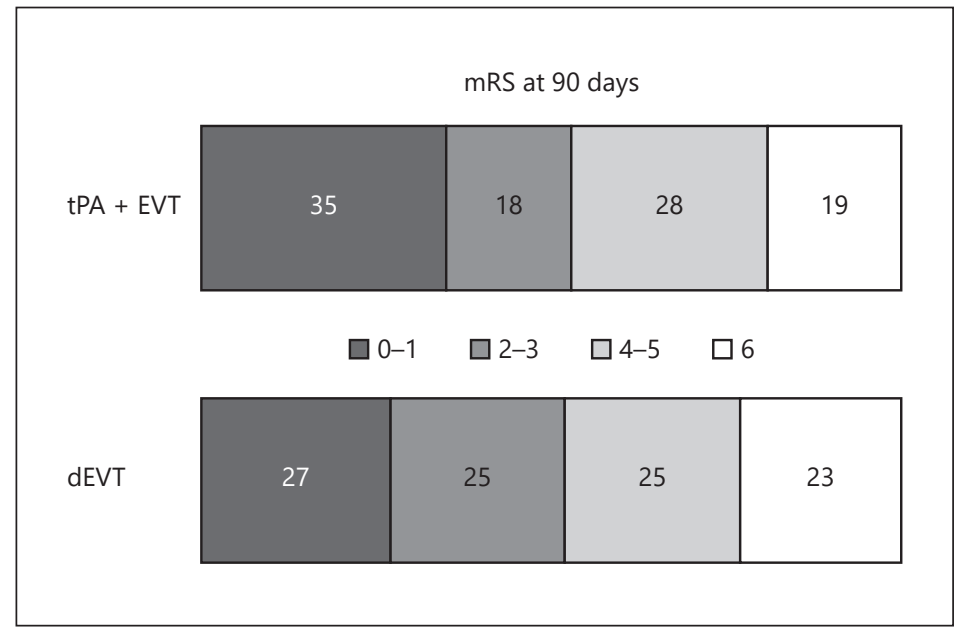

significantly longer in transfers (median [IQR] $4.1 \mathrm{~h}$ [3.3-5.1] vs. $2.5 \mathrm{~h}$ [1.7-3.5], $p=0.001$ ). While the rates of favorable reperfusion defined as a TICI score of $2 b$ or higher did not differ between the groups, the rates of complete reperfusion defined as TICI 3 were significantly higher in the dEVT group (75 vs. $61 \%, p=0.03$ ).

In-hospital mortality rates and discharge destinations did not differ between the treatment groups. Excellent outcome rates at discharge did not differ between the groups (22 vs. $16.5 \%, p=0.36$; Table 2). Functional outcome data at 90 days following stroke was available for $73(66 \%)$ patients in the dEVT group and $103(65 \%)$ patients in the bridging group. Similarly to the results observed at discharge, the rates of excellent functional outcome did not differ between the groups (27 vs. $35 \%, p=1$; Fig. 2; Table 2).

On multivariate regression analysis, treatment modality did not significantly modify the chances of excellent outcome at hospital discharge (OR 0.7, 95\% CI 0.3-1.5) or at 3 months (OR 0.8, 95\% CI 0.4-1.4; Fig. 3). However, admission NIHSS (OR 0.85, 95\% CI 0.780.92 per point), age (OR $0.96,95 \%$ CI $0.94-0.99$ per year), and time from symptom onset to groin puncture (OR $0.75,95 \%$ CI $0.59-0.93$ per $\mathrm{min}$ ) negatively impacted the chances for excellent outcome and major early recovery (Fig. 3). Similarly, treatment modality did not modify the chances for early major recovery (OR 1.64, 95\% CI 0.68-4.08), discharge to home (OR $0.67,95 \%$ CI $0.34-1.32$ ) or in-hospital mortality (OR 0.9 , 95\% CI $0.36-2.34$ ). The only variables that modified the chances for mortality were age and admission NIHSS (Fig. 3).

\section{Discussion}

In the current study, bridging and dEVT resulted in similar survival and favorable outcome rates in patients with ELVO. TICI $2 b-3$ reperfusion status was very frequent in patients treated with either bridging or dEVT corroborating findings from prior randomized studies [6-11]. Interestingly, however, the rates of complete reperfusion with a final TICI score of 3 were higher in the dEVT group. This may suggest that with larger numbers of included patients, a difference in outcome in favor of dEVT may become evident but this point needs to be proven in future studies. However, it should be noted that TICI 3 is just one potential modifier of outcome and futile recanalization in conjunction with poor collateral state and large ischemic core with high NIHSS has previously been described. 
Treat.: EVT + TPA (vs. EVT only)

Age (per 1 year)

Sex $=$ male

Stroke subtype $=$ cardioembolic, $\%$

NIHSS on admission

Time: onset to endovasc. proc. (per $1 \mathrm{~h}$ )

a

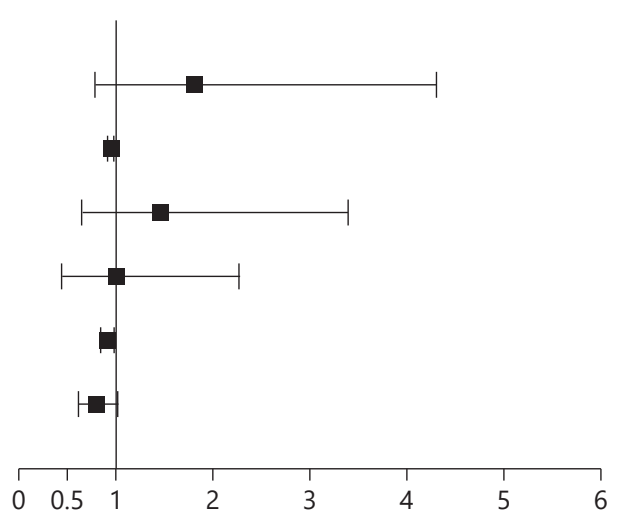

OR for NIHSS score - day $1<2$ with $95 \% \mathrm{Cl}$

Treat.: EVT + TPA (vs. EVT only)

Age (per 1 year)

Sex $=$ male

Stroke subtype = cardioembolic, $\%$

Time: onset to endovasc. proc. (per $1 \mathrm{~h}$ )

b

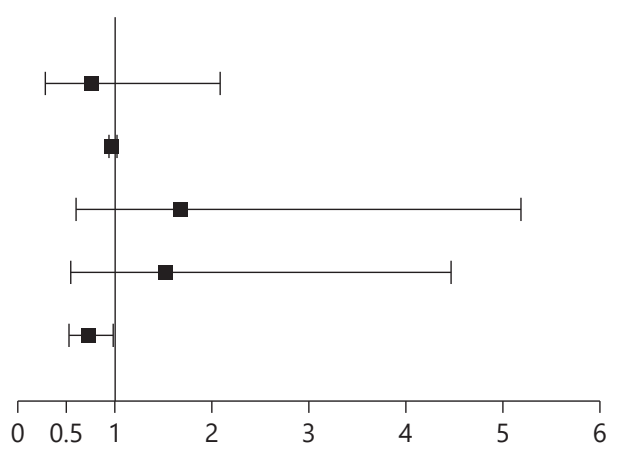

OR for in-hospital mortality with $95 \% \mathrm{CI}$

Treat.: EVT + TPA (vs. EVT only)

Age (per 1 year)

Sex $=$ male

Stroke subtype = cardioembolic, $\%$

NIHSS on admission

Time: onset to endovasc. proc. (per $1 \mathrm{~h}$ )

c

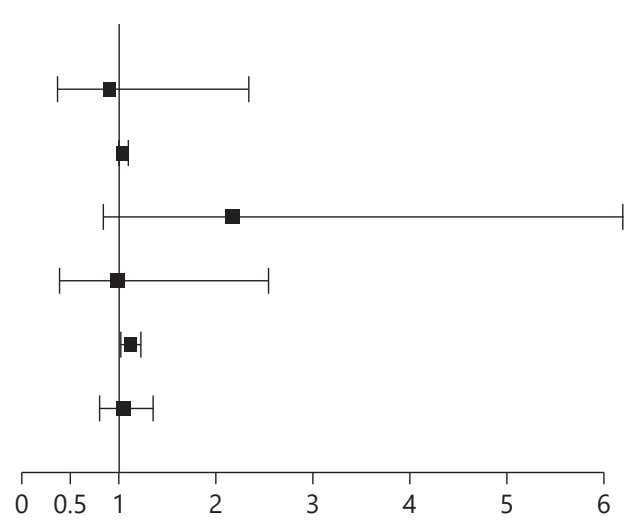

OR $(95 \% \mathrm{Cl})$

$1.8(0.79,4.3)$

$0.95(0.92,0.97)$

$1.46(0.64,3.39)$

$0.99(0.44,2.27)$

$0.91(0.83,0.98)$

$0.79(0.61,1.01)$

OR $(95 \% \mathrm{Cl})$

$0.76(0.28,2.08)$

$0.97(0.94,1.01)$

$1.68(0.6,5.18)$

$1.52(0.55,4.46)$

$0.73(0.52,0.97)$

OR $(95 \% \mathrm{Cl})$

$0.9(0.36,2.34)$

$1.04(1,1.09)$

$2.17(0.83,6.2)$

$0.97(0.38,2.53)$

$1.11(1.01,1.22)$

$1.04(0.79,1.35)$

Fig. 3. Odds ratios for factors included in the multivariate analyses for mRS scores 0-1 at 3 months following stroke (a), in-hospital mortality (b), favorable target vessel recanalization (TICI 3) at the end of EVT (c), and major early recovery defined as an 8-point drop in NIHSS or NIHSS 0-1 on day 1 following procedure (d). 


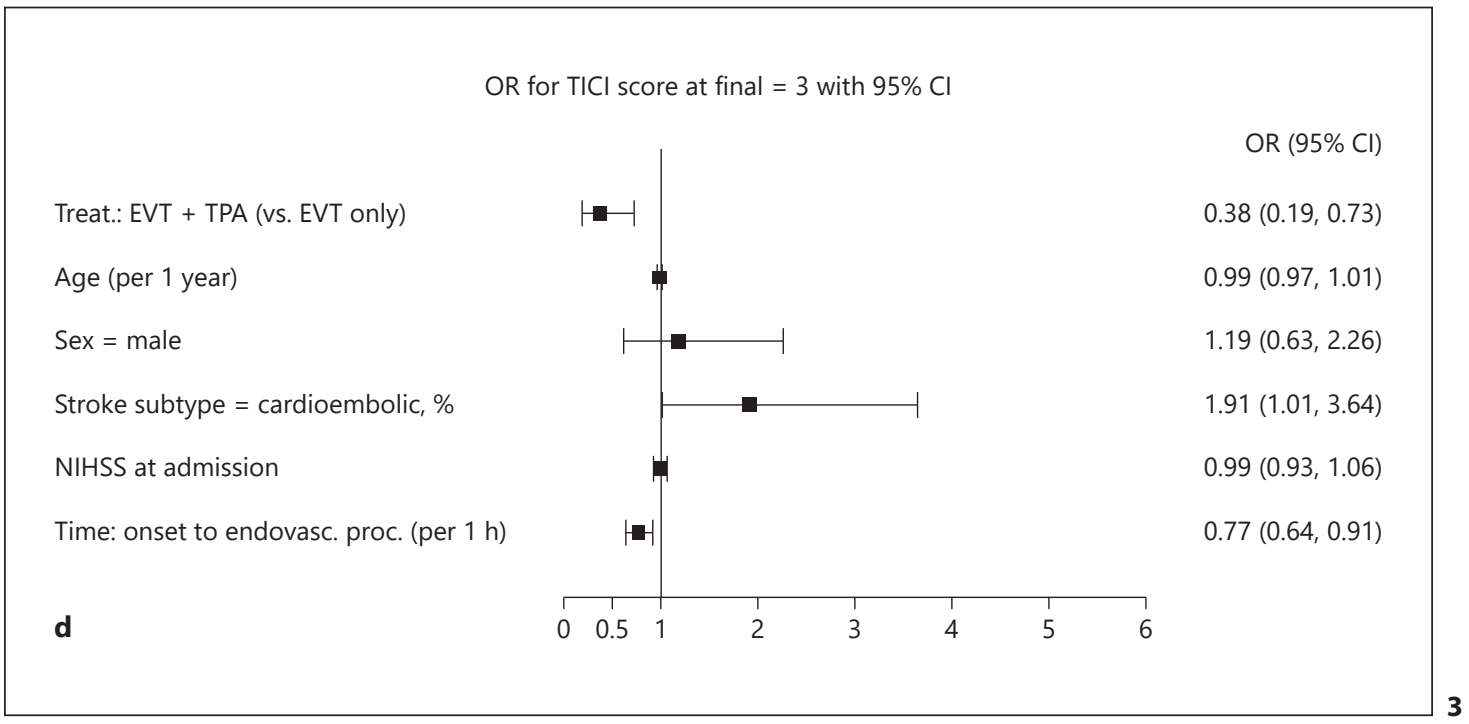

In the present study, age and admission NIHSS were identified as prognostic factors on multivariate analyses but treatment allocation did not influence outcome. This is in agreement with a smaller single-center pilot study that examined the effects of bridging versus dEVT on outcome and found no such impact [18] as well as with several other retrospective studies $[22,23,33-35]$ and prospective registry data [20, 21, 24] that did not find differences in outcome between patients treated with bridging and those treated with dEVT. In contrast, other retrospective studies found lower mortality rates [23], lower symptomatic hemorrhage rates and higher reperfusion rates in patients treated with dEVT [36] while two meta-analyses on the subject found evidence for lowering mortality and severe disability rates with bridging $[26,37]$.

The different outcomes observed in these studies probably stem from inhomogeneous patient populations, inconsistent outcome measures, and nonstandardized therapeutic protocols as well as from potential selection bias since in some studies patients were referred to dEVT based on the preference of the treating physician, while in others patients were referred to dEVT only if they had contraindications for tPA. Furthermore, some studies included patients presenting up to $7 \mathrm{~h}$ from onset, while others only included patients presenting within $4 \mathrm{~h}$ from symptom onset. Moreover, while thrombectomy devices were used in most studies, others primarily used aspiration devices [19, 23, 33, 38]. These differences probably account for the differences in outcomes observed across existing studies. In contrast, all included patients in the present study presented within $4 \mathrm{~h}$ of symptom onset and the vast majority were treated with stentriever devices.

At any rate, the conflicting data raise the need for a prospective randomized study to evaluate the two therapeutic strategies of bridging versus dEVT in patients with ELVO.

The data presented in the current study has the advantage of being prospective and of only including patients that presented within the time frame of otherwise being eligible for tPA. Most of the other studies on the topic included late presenters who would otherwise be ineligible for tPA and may have inherent poorer outcomes.

Of note, stroke severity and vascular risk factors were similar in both groups except for atrial fibrillation and congestive heart failure which were more frequent in the dEVT group. This imbalance may be due to the fact that patients with atrial fibrillation on anticoagulants had contraindications for tPA and thus for bridging. 
Importantly, time metrics including onset to recanalization did not significantly differ between the groups suggesting that bridging does not delay EVT. However, time from onset to EVT was prolonged in bridged patients that were transferred from other hospitals and this may suggest that in transfers significant delays may occur. Because our results further stress the role played by rapid reperfusion as a potent mediator influencing outcome for both EVT $[16,17]$ and bridging [39], the topic of delays caused by transfers should be studied in larger groups of patients in future randomized studies.

Our study has several limitations. First, the current study was not randomized and treatment allocations were made at the discretion of the treating physician. This may introduce selection bias as different centers and even different physicians in the same center may have different attitudes and prevailing clinical practices. Thus, while some emphasize administration of tPA in each eligible patient, others believe that in patients with internal carotid artery or basilar artery occlusions, the rates of recanalization with tPA are so small that patients would be better off with dEVT [2-5]. Since individual physician trends were not deliberately studied in this database, we do not have exact data as to how many patients were tPA eligible but were directly sent to dEVT based on the treating physicians' view that chances for obtaining recanalization with tPA are very low. This topic is very complicated because different variables including age, premorbid cognitive and functional status, and personal experience of the treating physician probably all factor in when making a decision of whether or not to skip tPA and go directly to EVT. Furthermore, local insurance companies do not mandate tPA administration prior to EVT. Second, the lack of finding significant differences in outcomes between the groups may also have been a result of our relatively small sample size. This is also suggested by the wide confidence interval observed. Third, given the lack of central imaging data, we could not assess the impact of collateral grade in the current study. Fourth, we do not have exact data on the number of patients that improved with tPA to the degree of not needing EVT. However, when we cross-referenced patients that presented with NIHSS scores over 10 and received tPA with those that were not given EVT because of rapid improvement, we could not find any patients with suspected ELVO and rapid improvement on tPA to the point of not needingEVT. Furthermore, judging from the literature, the percentage of patients with ELVO that improve with tPA is very small [2-5]. Finally, due to the format of data accrual, outcome data was categorized as excellent (mRS score 0-1), fair (mRS score 2-3), poor (mRS score 4-5) or death (mRS score 5). We cannot exclude the possibility that if we had classified outcome as favorable (mRS score $0-2$ ), fair (mRS score 3), poor (mRS score 4-5), and death (mRS score 6), the results may have been different, but this classification was unavailable to us at study completion. Due to these combined limitations, we believe that our results should be viewed as hypothesis-generating data that suggest the justification of future randomized studies. Nevertheless, our results are based on prospectively enrolled patients and all centers were large-volume centers with experienced stroke teams. Furthermore, our data may be viewed as replicating "real world" data outside of studies as they reflect the same gaps in knowledge that lead to the inconsistency observed in treatment allocations by different physicians.

In conclusion, for patients undergoing EVT, bridging and dEVT appear to lead to similar clinical outcomes with slightly better technical success (TICI 3) observed in patients undergoing dEVT. The equipoise to whether bridging provides additional benefits over dEVT should be resolved in future randomized controlled studies.

\section{Disclosure Statement}

All authors hereby declare they have no conflicts of interest. 


\section{Funding Sources}

This study was supported in part by unrestricted grants from Covidien and Stryker.

\section{Author Contributions}

R.R. Leker, J.E. Cohen, D. Tanne, N.E. Yaghmour: Research conceptualization and design, data collection, data analysis, manuscript drafting, review and editing.

D. Orion, G. Telman, Guy Raphaeli, J.Y. Streifler, J. Amsalem, H. Hallevi, P. Gavriliuc, N.M. Bornstein, Anat Horev: Data collection, critical manuscript review.

\section{References}

1 Hacke W, Schwab S, Horn M, Spranger M, De Georgia M, von Kummer R: "Malignant" middle cerebral artery territory infarction: clinical course and prognostic signs. Arch Neurol 1996;53:309-315.

2 Christou I, Felberg RA, Demchuk AM, Burgin WS, Malkoff M, Grotta JC, Alexandrov AV: Intravenous tissue plasminogen activator and flow improvement in acute ischemic stroke patients with internal carotid artery occlusion. J Neuroimaging 2002;12:119-123.

3 Derex L, Hermier M, Adeleine P, Pialat JB, Wiart M, Berthezene Y, Froment JC, Trouillas P, Nighoghossian N: Influence of the site of arterial occlusion on multiple baseline hemodynamic MRI parameters and post-thrombolytic recanalization in acute stroke. Neuroradiology 2004;46:883-887.

4 Lee KY, Han SW, Kim SH, Nam HS, Ahn SW, Kim DJ, Seo SH, Kim DI, Heo JH: Early recanalization after intravenous administration of recombinant tissue plasminogen activator as assessed by pre- and post-thrombolytic angiography in acute ischemic stroke patients. Stroke 2007;38:192-193.

5 Linfante I, Llinas RH, Selim M, Chaves C, Kumar S, Parker RA, Caplan LR, Schlaug G: Clinical and vascular outcome in internal carotid artery versus middle cerebral artery occlusions after intravenous tissue plasminogen activator. Stroke 2002;33:2066-2071.

6 Berkhemer OA, Fransen PS, Beumer D, van den Berg LA, Lingsma HF, Yoo AJ, Schonewille WJ, Vos JA, Nederkoorn PJ, Wermer MJ, et al: A randomized trial of intraarterial treatment for acute ischemic stroke. N Engl J Med 2015; 372:11-20.

7 Campbell BC, Donnan GA, Lees KR, Hacke W, Khatri P, Hill MD, Goyal M, Mitchell PJ, Saver JL, Diener HC, et al: Endovascular stent thrombectomy: the new standard of care for large vessel ischaemic stroke. Lancet Neurol 2015;14:846-854.

8 Campbell BC, Mitchell PJ, Kleinig TJ, Dewey HM, Churilov L, Yassi N, Yan B, Dowling RJ, Parsons MW, Oxley TJ, et al: Endovascular therapy for ischemic stroke with perfusion-imaging selection. N Engl J Med 2015;372:10091018.

9 Goyal M, Demchuk AM, Menon BK, Eesa M, Rempel JL, Thornton J, Roy D, Jovin TG, Willinsky RA, Sapkota BL, et al: Randomized assessment of rapid endovascular treatment of ischemic stroke. N Engl J Med 2015;372:10191030.

10 Jovin TG, Chamorro A, Cobo E, de Miquel MA, Molina CA, Rovira A, San Roman L, Serena J, Abilleira S, Ribo M, et al: Thrombectomy within 8 hours after symptom onset in ischemic stroke. N Engl J Med 2015;372:2296-2306.

11 Saver JL, Goyal M, Bonafe A, Diener HC, Levy EI, Pereira VM, Albers GW, Cognard C, Cohen DJ, Hacke W, et al: Stent-retriever thrombectomy after intravenous t-PA versus t-PA alone in stroke. N Engl J Med 2015;372:22852295.

12 Mazighi M, Meseguer E, Labreuche J, Amarenco P: Bridging therapy in acute ischemic stroke: a systematic review and meta-analysis. Stroke 2012;43:1302-1308.

13 Mazighi M, Serfaty JM, Labreuche J, Laissy JP, Meseguer E, Lavallee PC, Cabrejo L, Slaoui T, Guidoux C, Lapergue $\mathrm{B}$, et al: Comparison of intravenous alteplase with a combined intravenous-endovascular approach in patients with stroke and confirmed arterial occlusion (RECANALISE study): a prospective cohort study. Lancet Neurol 2009;8:802-809.

14 Rubiera M, Ribo M, Pagola J, Coscojuela P, Rodriguez-Luna D, Maisterra O, Ibarra B, Pineiro S, Meler P, Romero FJ, et al: Bridging intravenous-intra-arterial rescue strategy increases recanalization and the likelihood of a good outcome in nonresponder intravenous tissue plasminogen activator-treated patients: a case-control study. Stroke 2011;42:993-997.

15 Shi ZS, Loh Y, Walker G, Duckwiler GR: Endovascular thrombectomy for acute ischemic stroke in failed intravenous tissue plasminogen activator versus non-intravenous tissue plasminogen activator patients: revascularization and outcomes stratified by the site of arterial occlusions. Stroke 2010;41:1185-1192.

16 Khatri P, Yeatts SD, Mazighi M, Broderick JP, Liebeskind DS, Demchuk AM, Amarenco P, Carrozzella J, Spilker J, Foster LD, et al: Time to angiographic reperfusion and clinical outcome after acute ischaemic stroke: an analysis of data from the Interventional Management of Stroke (IMS III) phase 3 trial. Lancet Neurol 2014;13:567-574.

17 Khatri P, Abruzzo T, Yeatts SD, Nichols C, Broderick JP, Tomsick TA: Good clinical outcome after ischemic stroke with successful revascularization is time-dependent. Neurology 2009;73:1066-1072. 
18 Leker RR, Pikis S, Gomori JM, Cohen JE: Is bridging necessary? A pilot study of bridging versus primary stentriever-based endovascular reperfusion in large anterior circulation strokes. J Stroke Cerebrovasc Dis 2015;24: 1163-1167.

19 Sallustio F, Koch G, Di Legge S, Rossi C, Rizzato B, Napolitano S, Sama D, Arno N, Giordano A, Tropepi D, et al: Intra-arterial thrombectomy versus standard intravenous thrombolysis in patients with anterior circulation stroke caused by intracranial arterial occlusions: a single-center experience. J Stroke Cerebrovasc Dis 2013; 22:e323-e331.

20 Abilleira S, Ribera A, Cardona P, Rubiera M, Lopez-Cancio E, Amaro S, Rodriguez-Campello A, Camps-Renom P, Canovas D, de Miquel MA, et al: Outcomes after direct thrombectomy or combined intravenous and endovascular treatment are not different. Stroke 2017;48:375-378.

21 Bellwald S, Weber R, Dobrocky T, Nordmeyer H, Jung S, Hadisurya J, Mordasini P, Mono ML, Stracke CP, Sarikaya $\mathrm{H}$, et al: Direct mechanical intervention versus bridging therapy in stroke patients eligible for intravenous thrombolysis: a pooled analysis of 2 registries. Stroke 2017;48:3282-3288.

22 Bourcier R, Alexandre PL, Eugene F, Delasalle-Guyomarch B, Guillon B, Kerleroux B, Saleme S, Marnat G, Boucebci $\mathrm{S}$, Mirza M, et al: Is bridging therapy still required in stroke due to carotid artery terminus occlusions? J Neurointerv Surg 2018;10:625-628.

23 Broeg-Morvay A, Mordasini P, Bernasconi C, Buhlmann M, Pult F, Arnold M, Schroth G, Jung S, Mattle HP, Gralla $\mathrm{J}$, et al: Direct mechanical intervention versus combined intravenous and mechanical intervention in large artery anterior circulation stroke: a matched-pairs analysis. Stroke 2016;47:1037-1044.

24 Coutinho JM, Liebeskind DS, Slater LA, Nogueira RG, Clark W, Davalos A, Bonafe A, Jahan R, Fischer U, Gralla J, et al: Combined intravenous thrombolysis and thrombectomy vs thrombectomy alone for acute ischemic stroke: a pooled analysis of the SWIFT and STAR studies. JAMA Neurol 2017;74:268-274.

25 Goyal M, Menon BK, van Zwam WH, Dippel DW, Mitchell PJ, Demchuk AM, Davalos A, Majoie CB, van der Lugt A, de Miquel MA, et al: Endovascular thrombectomy after large-vessel ischaemic stroke: a meta-analysis of individual patient data from five randomised trials. Lancet 2016;387:1723-1731.

26 Tsivgoulis G, Katsanos AH, Mavridis D, Alexandrov AW, Magoufis G, Arthur A, Caso V, Schellinger PD, Alexandrov AV: Endovascular thrombectomy with or without systemic thrombolysis? Ther Adv Neurol Disord 2017;10: $151-160$

27 Fischer U, Kaesmacher J, Mendes Pereira V, Chapot R, Siddiqui AH, Froehler MT, Cognard C, Furlan AJ, Saver JL, Gralla J: Direct mechanical thrombectomy versus combined intravenous and mechanical thrombectomy in largeartery anterior circulation stroke: a topical review. Stroke 2017;48:2912-2918.

28 Adams HP Jr, Bendixen BH, Kappelle LJ, Biller J, Love BB, Gordon DL, Marsh EE 3rd: Classification of subtype of acute ischemic stroke. Definitions for use in a multicenter clinical trial. TOAST. Trial of Org 10,172 in Acute Stroke Treatment. Stroke 1993;24:35-41.

29 Saposnik G, Di Legge S, Webster F, Hachinski V: Predictors of major neurologic improvement after thrombolysis in acute stroke. Neurology 2005;65:1169-1174.

30 Higashida RT, Furlan AJ, Roberts H, Tomsick T, Connors B, Barr J, Dillon W, Warach S, Broderick J, Tilley B, et al: Trial design and reporting standards for intra-arterial cerebral thrombolysis for acute ischemic stroke. Stroke 2003;34:e109-e137.

31 Hacke W, Kaste M, Fieschi C, von Kummer R, Davalos A, Meier D, Larrue V, Bluhmki E, Davis S, Donnan G, et al: Randomised double-blind placebo-controlled trial of thrombolytic therapy with intravenous alteplase in acute ischaemic stroke (ECASS II). Second European-Australasian Acute Stroke Study Investigators. Lancet 1998;352: 1245-1251.

32 R Core Team: R: A Language and Environment for Statistical Computing. R Foundation for Statistical Computing, 2015.

33 Rai AT, Boo S, Buseman C, Adcock AK, Tarabishy AR, Miller MM, Roberts TD, Domico JR, Carpenter JS: Intravenous thrombolysis before endovascular therapy for large vessel strokes can lead to significantly higher hospital costs without improving outcomes. J Neurointerv Surg 2018;10:17-21.

34 Weber R, Nordmeyer H, Hadisurya J, Heddier M, Stauder M, Stracke P, Berger K, Chapot R: Comparison of outcome and interventional complication rate in patients with acute stroke treated with mechanical thrombectomy with and without bridging thrombolysis. J Neurointerv Surg 2017;9:229-233.

35 Wee CK, McAuliffe W, Phatouros CC, Phillips TJ, Blacker D, Singh TP, Baker E, Hankey GJ: Outcomes of endovascular thrombectomy with and without thrombolysis for acute large artery ischaemic stroke at a tertiary stroke centre. Cerebrovasc Dis Extra 2017;7:95-102.

36 Wang H, Zi W, Hao Y, Yang D, Shi Z, Lin M, Wang S, Liu W, Wang Z, Liu X, et al: Direct endovascular treatment: an alternative for bridging therapy in anterior circulation large-vessel occlusion stroke. Eur J Neurol 2017;24:935943.

37 Mistry EA, Mistry AM, Nakawah MO, Chitale RV, James RF, Volpi JJ, Fusco MR: Mechanical thrombectomy outcomes with and without intravenous thrombolysis in stroke patients: a meta-analysis. Stroke 2017;48:24502456.

38 Gerschenfeld G, Muresan IP, Blanc R, Obadia M, Abrivard M, Piotin M, Alamowitch S: Two paradigms for endovascular thrombectomy after intravenous thrombolysis for acute ischemic stroke. JAMA Neurol 2017;74:549556.

39 Rha JH, Saver JL: The impact of recanalization on ischemic stroke outcome: a meta-analysis. Stroke 2007;38: 967-973. 